\title{
The Body Image Project: Mobilizing Policy Research for Children's Health
}

\author{
Lorayne Robertson, Kalin Moon, Joli Scheidler-Benns \\ University of Ontario Institute of Technology
}

\begin{abstract}
Knowledge mobilization projects attempt to make theory and research available in order to inform policy and practice. This paper describes a knowledge mobilization project at a Canadian university. A database of Canadian health curriculum policies was analyzed to discern the general approaches to body image across the country. The findings show that learning how to cultivate a positive body image is inconsistently addressed across the education policies of the thirteen provinces and territories. Secondly, many Canadian curriculum policy documents have missed opportunities to teach acceptance of diverse body types and other protective factors. Third, health is more strongly associated with fitness in policies than with more holistic approaches. A knowledge mobilization website project was established to encourage more critical understandings of healthy self-esteem and body image. The website contains summaries of current research pertaining to body image, child and adolescent development, and key messages about body-positive health. The online and open source material available includes ageappropriate lessons for teachers and parents. These materials have been designed to translate research into activities, lessons, and key messages that promote healthy body image and self-esteem.
\end{abstract}

\section{Introduction}

One of the many advantages of access to the internet is the ability to find information literally "at the touch of a button." One example is a Health Canada website which provides fifty-two indicators of health for adults, as well as tips for improving your health [8]. The information provided is based on research. For those who choose to read more deeply, the website provides links to the research papers on which the tips and conclusions are based. This information allows adult Canadians to become more health literate as they select topics to research and weigh the findings of the researchers.

When it comes to the curriculum policies which delineate the learning outcomes for students in K-8 schools, there is no similar organization of consolidated information backed up by links to research for the consumers of the policies: Canadian teachers, students and parents. Efforts in this direction would help more of the Canadian population to build health literacy skills.

Sharing knowledge from research for practical purposes has been labelled knowledge mobilization by Levin [12]. Similarly, Desforges identifies the importance of sharing research through knowledge transformation in order to improve the human condition [5].

There is a contrast evident between the easy accessibility to health information in the Health Canada website and the information available to interested persons seeking access to Canadian health curriculum policies across the thirteen provinces and territories. First, the policies are not all easily accessible on the internet and they are organized differently from policy to policy [24]. Secondly, the approaches to health vary from province to province [27].

Curriculum policies, as with all education policies, may be revisions of earlier curriculum policies and may or may not cite established research. Education policies also reflect societal values - and it has been noted that "every dimension of schooling and every form of educational practice are politically contested spaces" As a result, if the political climate has been established as anti-obesity, health curriculum policies may focus on encouraging personal responsibility to be fit or to maintain a certain body size and shape, without referring to research which argues for the consideration that health is more complicated than a calories in and out approach would suggest [10]. Research has shown that multiple health determinants complicate the picture of a healthy body such as: heredity; access to a safe, supervised, play environment; and the availability of affordable, nutritious food choices [20]. One unintended result of emphasizing a simplistic solution to health is that students can feel unhappy, guilty, and responsible for their body size when the reality is that health is complex and socially and culturally-influenced [20].

Body image and body dissatisfaction and the lowered self-esteem associated with it are not unimportant. Body dissatisfaction is associated with anxiety and disordered eating, which impacts the physical, social and emotional health of children and adolescents [27]. Certain body sizes face prejudice throughout a lifetime [7]. Body-based dissatisfaction is associated with lower self-esteem and researchers 
see that schools are important places for intervention programs which promote active healthy lifestyles and building self-esteem. This type of approach can have a positive effect on other areas of help such as anxiety and depression [14].

Earlier versions of health curriculum policies in Canada traditionally advised students what not to do, such as promoting the avoidance of drugs, smoking, and early sexual behaviour [27]. In more recent times, Nutbeam proposes that schools help students develop health literacy skills in order "to make positive health behaviour choices" [17].

The knowledge mobilization research project described here is intended to encourage the inclusion of more complex definitions of child and adolescent health in Canadian curriculum policies as well as more realistic understandings of the importance of teaching greater acceptance of diverse body shapes and sizes for students' mental health and self-esteem.

\section{Research Rationale}

Policy analysis is a disciplined, systematic review of policies and is intended for constructive purposes. It offers a window into the values, assumptions, body-based discourses and politics present in formal health curriculum policies. In this case, it provides a means of examining the degree of knowledge mobilization of current theories advocating for more health literacy, as well as emergent health research on body image.

Canadian curriculum policies were examined for the consistency of their treatment of body image and related self-esteem and acceptance messages of diverse body shapes and sizes. Body image was selected as a focus because it is a topic of significance in schools and in society. School-aged children experience body-based stereotyping and stigma, as well as harassment and bullying based on their body size and appearance. In addition, bodybased acceptance has implications for mental health as well as physical health. There is evidence of the increasing incidence of disordered eating - both restricted eating and overeating in Canadian society [9] [15]. Understanding the contributing health and societal factors underlying these body-based issues is challenging and complex and needs to be reflected in policy [19] [20].

The research described in this paper examines the need for increased knowledge mobilization of both current health science theory and research in order to contribute to increased health literacy.

\section{Theoretical perspectives}

Analysis of the discourse in a curriculum policy can provide a window on the curriculum policy focus. For example, a simplistic approach to health is reflected in a policy which asks children to compare lunches for healthy foods. The policy in this case provides no evidence of considering also the complexity of social factors which do not enable all families to have equal access to healthy food, even if they want to eat in a healthy way.

Policy analysis can also indicate if policies have been influenced by earlier policies [4]. Current health curriculum policies are no different; they can carry with them the legacy of past priorities for disease prevention and with an emphasis on individual responsibility and risk avoidance [27].

Newer, more critical and emancipatory curriculum approaches are available which give greater recognition to complexity and to building students' health literacy levels. Reitz discusses a more empowering education that teaches a social intelligence to inspire political action [22].

Health literacy can be understood as the ability to access and understand health research in order to make an informed choice. In an era of new literacies and multiple literacies health literacy can become even more broadly conceived as a kind of mindfulness where students have more active roles in identifying and discussing health issues of significance and building capacity to address them [1] [9].

Nutbeam presents a continuum of health literacy approaches that are evident in school curriculum. These approaches reflect degrees of empowerment and recognition of complexity [17]. At the most basic level is functional health literacy which would include learning to follow instructions to avoid unhealthy practices. At the most empowered level, critical health literacy includes empowerment, social action and the recognition that multiple factors in addition to choice, such as the environment and the economy, can impact personal health [17]. Similarly, Chinn theorizes that critical health literacy includes the building of capacity and social action for individuals and communities [2]. More recently, Nutbeam has reconsidered critical health literacy as a set of literacies or social practices within different contexts rather than a singular literacy [18].

Critical health literacy or the ability to understand complexity and diversity is important because schools are places which are not necessarily friendly to children's bodies. Rich, Holroyd and Evans identified a simplistic approach to health in British policies which they term as healthism [23]. They find that peers, the media and cultures in schools create discourses around body perfection that contribute to problems with eating. Similarly, Kehler and Atkinson in the Canadian context find that boys and their body image are also impacted significantly by schools [9]. McDermott investigates one Canadian school's fitness program and has similar concerns, finding that initiatives to correct body size can be overly simplistic [13]. She also encourages a more critical examination of the impact of discourses of obesity and inactivity on students. 
In summary, health curriculum theorists over time have identified a need for more empowering approaches to health literacies which encourage understandings of complexity and diversity. At the same time, researchers identify risks to both girls and boys when the perfect body and shape is presented as desirable for the majority of children and adolescents through media and societal messages [9] [15]. Educational responses to these dual messages have not yet been thoroughly researched. Little is known, for example about how curriculum policies are responding to society's concerns about obesity [6]. Also, little is known regarding how Canadian health curriculum policies approach other body-based topics. Is the predominant approach to provide avoidance information and expect students to be personally responsible for following through? Do Canadian curriculum policies present opportunities for health empowerment and advocacy through more critical health literacy-based approaches? These questions formed the basis of the policy analysis.

A second key theoretical consideration is that of knowledge mobilization which requires structures to make research more accessible to parents, teachers, school personnel, and policy designers. Two elements need to be in place to support knowledge mobilization: 1) the knowledge user needs to seek out the information, and 2) processes need to be in place for the knowledge exchange to happen. In the specific case of the research on body image, there are potentially harmful effects on students from overmonitoring and surveillance as well as from exercise programs that are simplistic in their conception [13] [23].

In an era where the affordances of technology can be harnessed in order to provide information in an accessible format, there are increased opportunities for the sharing of both potentially helpful and potentially harmful messages. Yet to date, little has been written about how technology might be better harnessed for sharing health information that is research-based. Technology provides opportunities to not only mobilize research information but to gain information, ideas and links from the users of the websites.

While research and policy design are often distinct processes, technology can be used to build virtual bridges between the researchers and policy designers. The internet provides a forum for information sharing but it also provides a source for presenting powerful multi-media images. Often images can say more than words, and the combination of images, research information, and an accessible format can facilitate knowledge translation and mobilization.

\section{Methodology}

The research methodology for this study was primarily policy analysis, which led to the design of a knowledge mobilization website. Policy analysis involves examining how policies came to be, potential consequences of policies, and consideration of potential interventions to improve the policy development process and its outcomes [3]. As a first step, body-based health issues for children and adolescents were identified through a literature review on body image and disordered eating. Next, a continuum of approaches to the teaching of health was organized into a policy analysis framework [17]. Third, the health and physical education curriculum policies from the thirteen provinces and territories were organized into a searchable database. The policies were analyzed using searches for key words and blind review. When one of the key words was located in a policy, that section of the policy was examined to determine: 1) the overall approach of the curriculum to body image and whether or not acceptance of a wide range of body shapes and types was evident in the curriculum; 2) the overall curriculum approach to health (either simple or complex) and 3) the dominant discourse of the curriculum (i.e., avoidance, responsibility, or complexity and criticality). This analysis included the curriculum policies of all Canadian provinces and territories.

\section{Findings}

One of the findings of this study is that the analysis of the current health curriculum policies across Canada presents a broken front in multiple ways. First, the affordances of technology for sharing curriculum policies across Canada have not been fully realized. Online access to digital curriculum policies across provinces and territories varies; as well, there is a wide variation in the organization and presentation of web sites. Some are searchable, for example, while others are a series of PDF documents. In addition to the confusion of diverse formats and web presentations of curriculum policies, the use of similar terms attached to different meanings from province to province creates challenges for analysis and comparison [24]. There is little agreement on the organizers for the presentation of curriculum policies (e.g., which grades or which subjects are combined within a curriculum policy) and, in addition, little agreement on the key health topics to be included in the policies.

With respect to body image, there is no national approach to body image and there is little coherence from province to province on this topic [25]. While there is an accumulation of evidence that Canadian children are undertaking disordered eating, this topic is not addressed in any consistent way across the individual health curriculum policies, nor is there coherence evident across grades or years within individual curriculum policies [15]. Two of the thirteen Canadian provinces and territories address 
body image in a consistent way across the grades. In addition, there appears to be little evidence that the cautions from health science research around regulating and monitoring students' size, fitness and food intake have been considered [25].

Further, it appears that the health research on body image has not been mobilized across provincial curriculum policies. For example, there are few indications that health curriculum policies have recognized that body image concerns begin well before adolescence and can persist into adult life. In addition, little attention has been given to boys and their body image concerns. The outdated approach that conceptualizes body image as a phenomenon that concerns a small number of adolescent girls persists [25].

With respect to approaches to the teaching of health, two concerns emerged. First, despite national health indicators and national agreement on the determinants of health, there is little agreement on the key topics that should be addressed across health curriculum policies. There are also multiple, diverse approaches to the teaching of health [27]. As well as a lack of coherence, the findings of this study present a national picture of missed opportunities for progressive and emancipatory approaches to health curriculum policies. There is room for recognition of how traditional approaches to the teaching of health that are simplistic (such as calories in and calories out) compare to the complexity of students' current realities of unequal opportunities for low-cost nutrition and exercise. To present health outcomes as predominantly choices misses key opportunities for more inclusive and empowering curriculum to address inequality.

The findings of this study indicate that there is room in the present Canadian health curriculum policies to re-consider traditional approaches to health that imply that students need to be given the right information and that this will result in healthy choices. This information is not only simplistic, but it privileges certain body types that will be more likely to attain an ideal size if they eat and exercise a certain way. Many health curriculum policies also, in general, are missing opportunities to help students resist mediated representations of the ideal body type.

Our research also indicates that some Canadian health curriculum policies have missed opportunities to help students build more critical understandings of health as a complex entity that includes physical, social and emotional health.

Combined, these results suggest that increased knowledge mobilization of research from health sciences and health curriculum theorists could be used toward building more critical body literacy understandings.

\section{Conclusion}

Based on the findings from this research, a knowledge mobilization project was undertaken at one university. The project involved pre-service teachers, graduate students, community partners, and professors. The website was in a design phase for one year, and was released in September, 2013. The website provides teachers and parents with key messages based on current research on body image from the field of health sciences. The intended audience for the website are the teachers and parents of children ages 1-13 who are seeking information that will help dispel myths about body shape and size. The website focuses on holistic ideas of health, including balance and well-being, including physical, social-emotional, mental and spiritual health. Most importantly the teachbodyimage.org website is available to anyone with online access.

The website includes child and adolescent development charts which show physical and emotional growth and development characteristics, and their implications for body image at different stages of students' school careers. In addition, the website provides key messages about body image from the research across eleven topics related to critical body literacy, such as media literacy, bodybased bullying, and social comparison. The website also includes lessons for teachers for students from K-8 in an effort to raise awareness and encourage conversations to promote health literacy. The content and design of the website are explored in more depth below.

An important aspect of knowledge mobilization is providing information in a format that can be searchable and useful for the audience. In the body image website, summaries of the research provide teachers and parents with information. For example, the research indicates that teachers who address body image require support to change personal beliefs about their own body image in order to help the students. Increasing parent and teacher efficacy in teaching about body image helps to support the students when they have questions. The research also supports integrating body image and self-esteem teaching across subject content areas in order to support all students.

One key innovative feature of the website is the child development charts which illustrate typical development broken down into cognitive, social, and physical growth categories at a glance. Specific body image implications connect to growth and development and are highlighted in a single column for clarification. Some surprising information is included which emphasizes the importance of early teaching about body image. The website reports that girls as young as five think their ideal body size are smaller than their existing body size and that thinner people are nicer. On the other hand, children at a 
very young age cab begin associating the idea of fat with lazy, stupid, or ugly [26].

Other segments of the website deal with media and some of the risks that media can present to a positive body image. Research indicates that media exposure continues to increase the risk of dieting in girls as young as 10 years old [26]. Boys also began managing their body appearance during this age with muscle gaining behaviours. For girls, body-based harassment can begin as early as 8 years old [26].

The child and adolescent development charts also provide critical insights into activities that teachers and parents can do and say to help all children feel better about their bodies and raise their self-esteem. In some cases, the website lists things not to do, such as to talk about dieting, complain about one's own body, and over-monitor everything that a child is eating.

From the research on child development as well as body image and self-esteem, the research team was able to compile a list of "key" body positive messages which are broken down into the following 11 critical health literacy categories: defining health, bullying, body image, self-esteem, healthy eating, role models, stereotyping, media literacy, advertising, active living and social comparisons. These messages underline the positive way to mobilize knowledge to our children.

Defining health is important because the focus should not be on the appearance, shape, or size of the child, but on the overall well-being of the child, spiritually, mentally, emotionally and physically. A healthy child is a full participant in life. Issues of bullying are harmful to the child's self-esteem and body-based bullying is often linked to stereotypical and racial discrimination. Body image instruction is valuable because children learn that people come in different shapes and sizes; body-based teasing can be hurtful and internalized for life [26]. Learning about self-esteem allows children to focus on other positive aspects about themselves that are not related to appearance. Fostering an atmosphere of acceptance and respect teaches students that they are all worthy of the same acceptance and respect.

The healthy eating messages teach the students to pay attention to their own body's cues for thirst, hunger, rest, and exercise. In this way they learn to honour their body; the focus remains on nutrients not calories as a way to give their body what it needs. Positive role models for children are imperative for optimal growth. Adults serving children should become aware of their own biases and model body positive messages. Dieting should not be modelled for children and the word diet should not be used around them.

Stereotypes in general are harmful and the children can learn how to explore bias, stigma, and various forms of discrimination. Breaking down stereotypes allows children to celebrate their differences and uniqueness in positive ways. Critical media literacy is a powerful way for children to explore media content and the role that media plays in a consumer driven society. Advertising is about making profits and the ideal images that are 'sold' to the public are there for that purpose. As children learn about the social, cultural, and historical construction of media and advertising, they become empowered by becoming informed consumers.

Active living validates many types of activities for exercise and health, not just competitive sports. Encouraging the joy of movement in all of our children stimulates an enjoyment of exercise. Comparing students and competitive activity related to body image and appearance should not be the focus. Children should be complimented on the things that they do and the effort that they give instead of their appearance. Students should be discouraged from making these comparisons as well and should learn to measure their own success against personal goals that include activity and exercise. Making social comparisons based on clothing and gender should be discouraged as well. By focusing on these messages, teachers and parents can support children's well-being and encourage the goals of life-long participation in life and health.

On the website the following key messages for body image are included:

1. Comments about someone's appearance are often internalized for life.

2. Body size is determined by many factors such as genetics, access to health care, education, and the environment, and should not be viewed as merely individual choice and personal responsibility. Schools should avoid activities that focus on regulation and surveillance of food choices.

3. Body Image is an issue for males and females of all ages. Boys feel pressure to be muscular. Girls feel pressure to be thin.

4. There is no such thing as the perfect size or shape.

5. Body shapes and sizes are naturally diverse as is everything else in nature.

6. How body shapes and sizes are valued changes with history, culture, gender and age groups.

7. All ages and genders can be impacted by weight and eating preoccupations.

8. The clothes we wear are part of our body image.

9. Our society places an unnatural emphasis on appearance over competence.

These key messages might, at first, appear to be rather simplistic in their presentation, yet each message was carefully distilled from the research on body image which was available from the field of health sciences. Each topic or category has teacher- 
designed lessons for each age group which are ready to use for teachers, including the clickable links for books or videos. If there is limited time, there are body-positive 'booster' activities available to continue body positive dialogue in the classroom. The information is easy to share with other teachers by copying the link.

The website itself is child and adolescentfocused. The opening pages provide parents and teachers with a view of children's thoughts about body image. Parents who follow the links from these thoughts can find key body positive messages to give to their son or daughter about health and having a positive body image.

The Child Says graphics in the Why Teach Body Image section present an opportunity for parents and teachers to take a look into the minds of students and offers tools to: a) help them understand why they feel a certain way and b) empower them to think critically about their personal health and body acceptance.

The research team labelled this section "Why Teach Body Image?" to emphasize recent research indicating that children and adolescents at increasingly younger ages are beginning to think negatively about their body image and are taking steps to change the way they look, not for health reasons, but due to peer and societal pressures. The primary mentors for students: parents and teachers, need to become aware of how children and adolescents feel and to outfit them with the tools to make healthy mental, physical, social and emotional choices. Why Teach Body Image graphically displays the concerns children and adolescents articulate and stresses the importance of addressing them.

The section also aggregates knowledge from the fields of psychology and public health. Drawing from the child development charts, each graphic presents the information in a way that is easy to understand and self-guided, allowing for both sequential thinking (a single topic) and lateral thinking (a series of interrelated topics). For example, Figure 1 displays a child in the age range of four to seven years old. Surrounding her are thoughts reflective of body image focused cognitive processing of children at that age within the context of current societal pressures and 'norms'. As early as age five children begin to identify smaller body size with positive characteristics [26]. They begin to acquire a sense of self, which is strongly influenced by the role models in their lives, their peers and the media. The research can be surprising to parents and teachers and may provoke the user to learn more by clicking on the thoughts articulated in the child's dialogue bubble.

When a user clicks on a thought, they are presented with a brief description of the psychological research behind the thought, followed by lesson suggestions and the key messages that can help students understand and modify their perceptions. Links are provided that can take the user to the appropriate lesson(s). This section provokes users to think about what it is important to teach children and adolescents about body image, and then leads users to content to help them address the issues.

Overall, the materials available on the website and its design attempt to address many of the missed opportunities found during the pan-Canadian health curriculum policy analysis process. Web-based platforms have been shown to be effective tools for increasing teachers' knowledge and comfort with some body image lessons [16]. The teachbodyimage.org website is designed to be an easy to navigate, engaging and accessible resource for all Canadian teachers and parents. It is a source for up to date information regarding body image for those living in provinces or territories without easy access to their school curriculum online and/or those living in areas where educational policy does not reflect current research on body image. The content

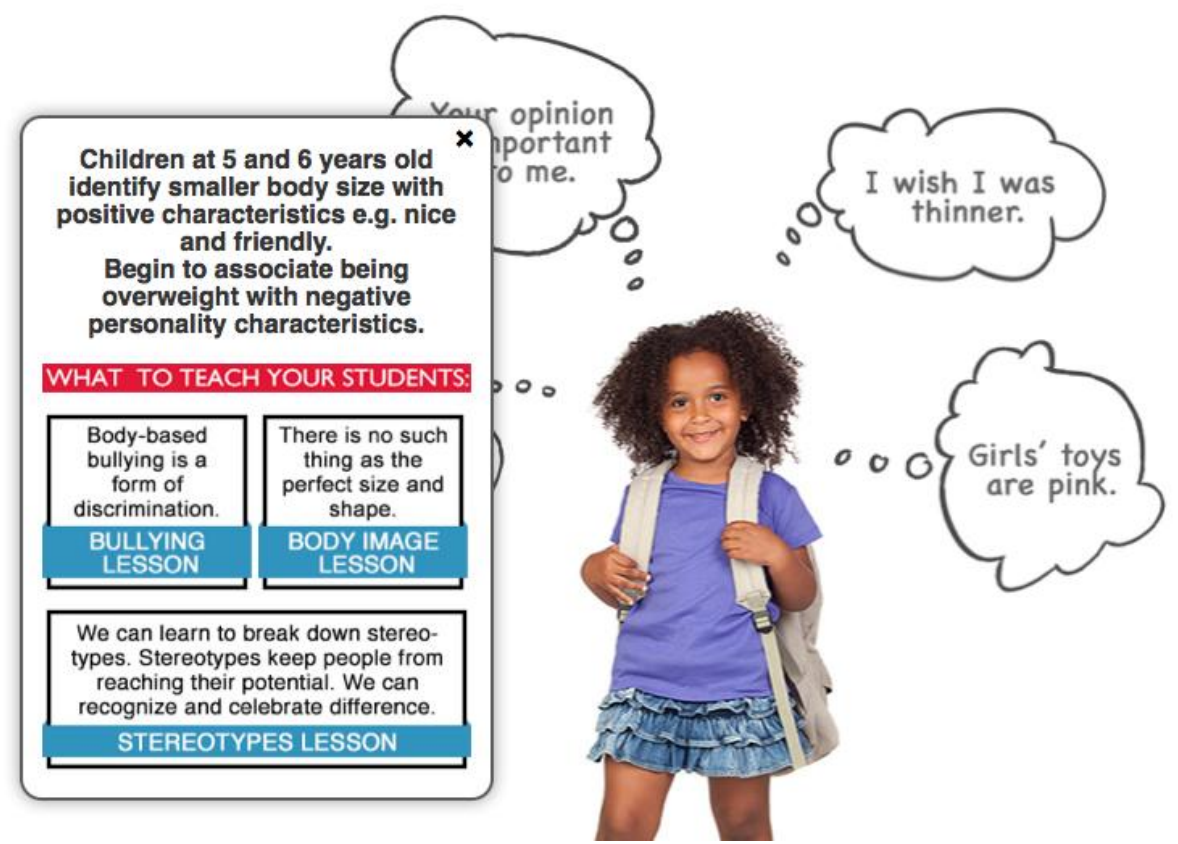

Figure 1. Child aged 4-7 (K-3). From teachbodyimage.org Why Teach Body Image? Section. 
was made by teachers, for teachers, with the students at the centre of each activity.

As the website develops, another potential area of expansion to be considered will be building collaborative communities who are interested in body image, self-esteem, and holistic health. While the affordances of Web 1.0 allow for access to websites, research summaries and information, the affordances of the Web 2.0 environment allow for more sharing of information through email, blogs and discussion boards. Social media tools such as Twitter and Facebook can provide links between the teachbodyimage.org site and other sites such the National Eating Disorder Information Centre (nedic.ca) and other social agencies that are committed to research-based knowledge translation for their constituent groups.

Another area of potential expansion of the website will be to include the voices of adolescents as they share their concerns and issues surrounding selfesteem, mental health, body-based teasing and bullying, and other related health topics. These new additions, made possible through networks and technology affordances, can be harnessed to share research knowledge with the goal of effecting positive changes for child and adolescent health.

\section{Acknowledgements}

This research was made possible by a grant from KNAER, Knowledge Network for Applied Education Research (www.knaer-recrae,ca). Thanks to NEDIC Director Merryl Bear, and Girls Inc. Durham Executive Director, Yvette Nechvatal-Drew, for their guidance and partnership throughout this project. Special thanks to Dr. Dianne Thomson for her contributions.

\section{References}

[1] Anderson, A. \& Booth, D. (2006). Health literacy. In Stones in the sneaker: Active theory for secondary school physical and health educators. Singleton, E., Varpalotai, A. (Eds). London: The Althouse Press.

[2] Chinn, D. (2011). Critical health literacy: A review and critical analysis. Social science \& medicine, 73, 60-67.

[3] Collins, T. (2005). Health policy analysis: A simple tool for policy makers. Public Health, 119 (3), 192-196. [4] Darling-Hammond, L. (1990). Instructional policy into practice: "The power of the bottom over the top". Educational Evaluation and Policy Analysis 12, 339-347.

[5] DesForges, C. (2001). Putting educational research to use through knowledge transformation: the agency comment. Keynote lecture to the Further Education Research Conference.

[6] Gard, M. (2011). The end of the obesity epidemic. New York: Rutledge.
[7] Grogan, S. (2008). Body Image: Understanding body dissatisfaction in men, women and children. New York: Routledge.

[8] Health Canada (2010). Healthy Canadians-A Federal Report on Comparable Health Indicators 2010. Retrieved March 2014 @ http://www.hc-sc.gc.ca/hcssss/pubs/system-regime/2010-fed-comp-indicat/indexeng.php

[9] Kehler, M. \&Atkinson, M. (2010) Eds. Boys' bodies: speaking the unspoken. New York: Peter Lang Publishing.

[10] Kincheloe, J. (2005). Critical Pedagogy Primer. Peter Lang: New York.

[11] Levin, B. (2008a). Curriculum policy and the politics of what should be learned in schools. In Connelly, F. (Ed.), The Sage Handbook of Curriculum and Instruction. Los Angeles: Sage.

[12] Levin, B. (2008b). Thinking about knowledge mobilization. Paper presented at the An Invitational Symposium Sponsored by the Canadian Council on Learning and the Social Sciences and Humanities Research Council of Canada, Vancouver.

[13] McDermott, L. (2012). 'Thrash yourself Thursday': the protection of the 'healthy' child through a fitness-based PE practice. Sport, Education and Society, 17(3), 405-429.

[14] McVey, G. (2003). What we have learned about primary prevention of food and weight preoccupation. National Eating Disorder Information Center. Retrieved March 2014 @ http://nedic.ca/what-we-have-learnedabout-primary-prevention-food-and-weight-preoccupation

[15] McVey, G., Tweed, S. \& Blackmore, E. (2004). Dieting among preadolescent and young adolescent females. Canadian Medical Association Journal. 170 (10). $1559-1561$.

[16] McVey, G.L., Gusella, J., Tweed S, \& Ferrari M. (2009). A controlled evaluation of web-based training for teachers and public health practitioners on the prevention of eating disorders. Eating Disorders: $J$ of Treatment and Prevention, 17(1), 1-26.

[17] Nutbeam, D. (2000). Health literacy as a public health goal: a challenge for contemporary health education and communication strategies into the 21 st century. Health Promotion International, 15 (3), 259-267.

[18] Nutbeam, D. (2009). Defining and measuring health literacy: what can we learn from literacy studies? International Journal of Public Health, 54, 303-305.

[19] Raine, K. (2005). Determinants of healthy eating in Canada: an overview and synthesis. Canadian Journal of Public Health. 96. S8-S14.

[20] Raphael, D. \& Bryant, T. (2002). The limitations of population health as a model for a new public health. Health Promotion International. Oxford University Press. 17 (2) 189-199. 
[21] Raphael, D. (2009). (Ed.) Social Determinants of Health: Canadian Perspectives. (2nd ed.). Toronto, ON: Canadian Scholars' Press Inc.

[22] Reitz, C. (2000). Liberating the critical in critical theory: Marcuse, Marx, and a pedagogy of the oppressed: alienation, art and the humanities. In Freirean pedagogy, praxis, and possibilities: projects for the new millennium, S. Steiner, H. Krank, P. McLaren, R. Bahruth, (Eds.) New York: Falmer.

[23] Rich, E., Holroyd, E., \& Evans, P. (2004). 'Hungry to be noticed: young women, anorexia and schooling, In J. Evans, B. Davies \& J. Wright (Eds.) Body knowledge and control: studies in the sociology of physical education and health. London: Rutledge.

[24] Robertson, L., \& Thomson, D. (2011). Watching bald eagles change shifts: Seeking Digital Curriculum Access across Canada. Alberta Journal of Education Research (AJER). 57(3) Fall 2011, 316-335.

[25] Robertson, L. \& Thomson, D. (2012). "Being a certain way: Seeking Body Image in Canadian health and physical education curriculum policies. Canadian Journal of Education, 35 (2), 334-354. Canadian Society for the Study of Education.

[26] Robertson L. \& Thomson, D. (2013). Website content. Retrieved March 2014@teachbodyimage.org

[27] Thomson, D. \& Robertson, L. (2012). Health curriculum policy analysis as a catalyst for educational change in Canada. Journal of education and learning, 1(1), 129-144.

[28] Smolak, L. \& Thompson, J.K. (2009). (Eds.) Body image, eating disorders and obesity in youth: Assessment, prevention and treatment. Washington, DC: American Psychological Association. 